\title{
PERSPECTIVE
}

\section{CRISPR-Cas Technology In and Out of the Classroom}

\author{
Lina Dahlberg and Anna M. Groat Carmona
}

\begin{abstract}
Student-centered practices, including student-focused research opportunities, enhance biology education and comprehension. One way to support student interest is through research opportunities in faculty laboratories. However, alternatives to traditional research apprenticeships are important for the inclusion of more undergraduate students in CRISPR-Cas-based research. Student interest in CRISPR-Cas technologies serves as a timely focal point for deepening undergraduate student engagement in biology courses. In this article, we describe some of the ongoing efforts to bring CRISPR-Cas technology out of the classroom and into the teaching laboratory.
\end{abstract}

\section{Introduction}

The most effective biology teaching actively engages students in their classrooms and coursework through group-work, activities, and discussion, which all access higher-order thinking and problem-solving skills. ${ }^{1}$ While student-centered classroom teaching, including reading primary literature articles, can enhance students' understanding of complex biological topics, an additional way to bring undergraduate students into the discussion is through research opportunities outside of the traditional lecture or seminar classroom.

The widespread interest in CRISPR* and its subsequent use as a technological tool in concert with Cas nucleases provides a direct link between student interest and biology instruction. In-depth conversations about the biochemical and ethical nuances of CRISPR-Cas-based technologies are topics that undergraduate biology students gravitate toward, in part because of the widespread "user-friendly" descriptions of CRISPR-Cas technology (i.e., precise genome editing and gene expression modulation) that are available through the news and social media. Educators are therefore in a powerful position to help counteract misconceptions or biases that students may bring to the classroom by engaging students in CRISPR-Cas-based research programs. Formal discussions of how the CRISPR-Cas systems were discovered and how they are being used,

*Clustered Regularly Interspaced Short Palindromic Repeats. exploited, and modified ensures that graduates from undergraduate institutions in biology-related departments and programs can enhance the discourse around genetic engineering and genomic technologies.

In this essay, we describe a variety of approaches that are currently being used to address the scientific basis, limitations, and misunderstandings surrounding CRISPR-Cas technologies by bringing students beyond lectures or interactive classroom activities. While our discussion here largely represents published or publicized work, we are aware that many instructors are currently carrying out this work at diverse institutions. We specifically hope that this essay will inspire others to bring discussions of CRISPRCas technology to as-yet unserved or underserved undergraduate populations. We highlight novel implementations of CRISPR-Cas technology in laboratory-based courses, including ongoing projects, though we also suggest ideas for potential educational collaborations.

\section{Faculty Research Opportunities}

Introducing undergraduate students to research through faculty laboratory experiences increases the students' sense of scientific identity and constitutes an especially powerful learning tool for students from traditionally underrepresented groups. ${ }^{2,3}$ Students who participate in research programs before graduation often have increased comprehension of biological concepts and self-report higher confidence in their science learning. ${ }^{2,4,5}$ Moreover,

Biology Department, Western Washington University, Bellingham, Washington.

Address correspondence to: Lina Dahlberg, Biology Department, Western Washington University, 516 High Street, Bellingham WA, 98225, E-mail: lina.dahlberg@wwu.edu

Dr. Lina Dahlberg and Dr. Anna Groat Carmona contributed equally to the research for, and writing of, this article. Lina Dahlberg conceived of the idea for this article. Both co-authors have reviewed and approved of the manuscript prior to submission.

(c) Lina Dahlberg and Anna M. Groat Carmona 2018; Published by Mary Ann Liebert, Inc. This Open Access article is distributed under the terms of the Creative Commons Attribution Noncommercial License (http://creativecommons.org/licenses/by-nc/4.0/) which permits any noncommercial use, distribution, and reproduction in any medium, provided the original author(s) and the source are cited. 
they often receive focused training in the field of their choice, introductions into the language and culture of science, and increased access to mentorship. ${ }^{6-8}$ Thus, student excitement around CRISPR and CRISPR-based technologies adds another layer of possibility to research experiences: the chance to learn-first-hand-how cuttingedge science is done and how it is evolving.

There are many models that offer research experiences to currently enrolled undergraduate students, including intensive training opportunities funded by the National Science Foundation, National Institutes of Health, and Howard Hughes Medical Institute. These programs place students in active research laboratories providing them opportunities to participate (often over the course of 10 weeks during the summer) in potentially high-profile, cutting-edge research. In particular, a growing number of these programs allow students to interact with technologies, such as CRISPR-Cas, as part of their research projects. Other examples of intensive, nonacademic research opportunities that are putting increased focus on having students use CRISPR-Cas technologies include outreach initiatives run by private industries (e.g., Jackson Laboratories), nonprofit organizations (e.g., Innovative Genomics), and competitive university partnerships (e.g., International Genetically Engineered Machine). ${ }^{9-11}$ These programs tend to be selective (requiring individual or team applications), but they provide participants with the chance to build or be a part of a student-driven research program. For individuals with the mentorship and/or other support to participate, intensive training programs such as those funded by federal or other sources are invaluable for understanding the fundamental principles behind as well as the research being done with CRISPR-Cas systems. Moreover, they provide undergraduate students with the opportunities to use the technologies to solve emerging problems.

Course-Based Undergraduate Research Experiences Because research opportunities for undergraduate students promote retention in STEM fields and solidify STEM identities, many educators are introducing their own students to scientific research at their home institutions. ${ }^{3}$ One strategy is through the introduction of Course-Based Undergraduate Research Experiences (CUREs) into undergraduate curricula. ${ }^{12-16}$ CUREs often have students plan and execute a series of experiments that are directed at solving a scientific problem, sometimes in direct connection with the research interests of the faculty teaching the course. ${ }^{4,14,17-21}$ Often, these research projects are a quarter, semester, or year in length and guide students through one or more aspects of a larger research project. In some cases, these experiences can be used to generate both laboratory reagents and data as well as data pertaining to student outcomes resulting from the implementation of CUREs. ${ }^{21-26}$ Table 1 lists a se- lection of recent courses that have been established to take advantage of student and community interest in CRISPRCas technology by engaging undergraduate students in CRISPR-Cas-based CUREs.

Given student interest and the increased need to communicate cutting-edge research to undergraduate students, colleges and universities have begun instituting CRISPR-Casrelated CUREs with great success. Part of the reason why CUREs and other forms of course-based research that utilize CRISPR-Cas technologies are successful is due to the current curricula in molecular biology-based laboratory courses at diverse academic institutions, particularly fouryear colleges and universities. Undergraduate students with molecular biology interests often take laboratorybased courses that teach them how to perform polymerase chain reactions (PCRs), genomic and plasmid DNA extractions, plasmid design and construction, restriction digests, primer design, and the techniques necessary to create transgenic organisms (i.e., Escherichia coli, Caenorhabditis elegans, etc,). These molecular techniques are valuable resources for undergraduates entering the biomedical or biotechnology workforce, but they also provide a preexisting framework that easily lends itself to instituting CRISPRCas-based CUREs. Such CUREs can be an exciting opportunity for undergraduate students to hone their previous knowledge of molecular biological techniques by engaging in CRISPR-Cas research firsthand. Thus far, no institution has reported a CRISPR-Cas-based CURE that transitions students in CRISPR-Cas technology from start to finish, likely due to time constraints. However, a limited scientific scope can still provide sufficient rationale for student work. There is increasing interest in developing CUREs that incorporate CRISPR-Cas technologies. Readers who are inspired to develop their own CUREs using CRISPR-Cas may be interested in workshops such as the one offered in advance of the 2018 Association for Biology Laboratory Education (ABLE).$^{\dagger}$ These workshops help participants hone ideas and plan curricula in hands-on, collaborative forums. ${ }^{\dagger}$

Postsecondary institutions that have implemented a CRISPR-Cas research component into their preexisting coursework report increased student engagement. For example, a collaboration between Rollins College and Stetson University has led to an ongoing CRISPR-based CURE with students reporting better understanding of the possible applications of using plasmid-editing tools to study multifaceted issues in molecular biology (J. Pieczynski, Rollins College, H. L. Kee, Stetson University, personal communication). CUREs can also feed directly into faculty research, where instructors will use their

†http://www.ableweb.org/conferences/able2018/pre-conference-workshop-onintegrating-crispr-cas9-into-the-undergraduate-classroom/ 


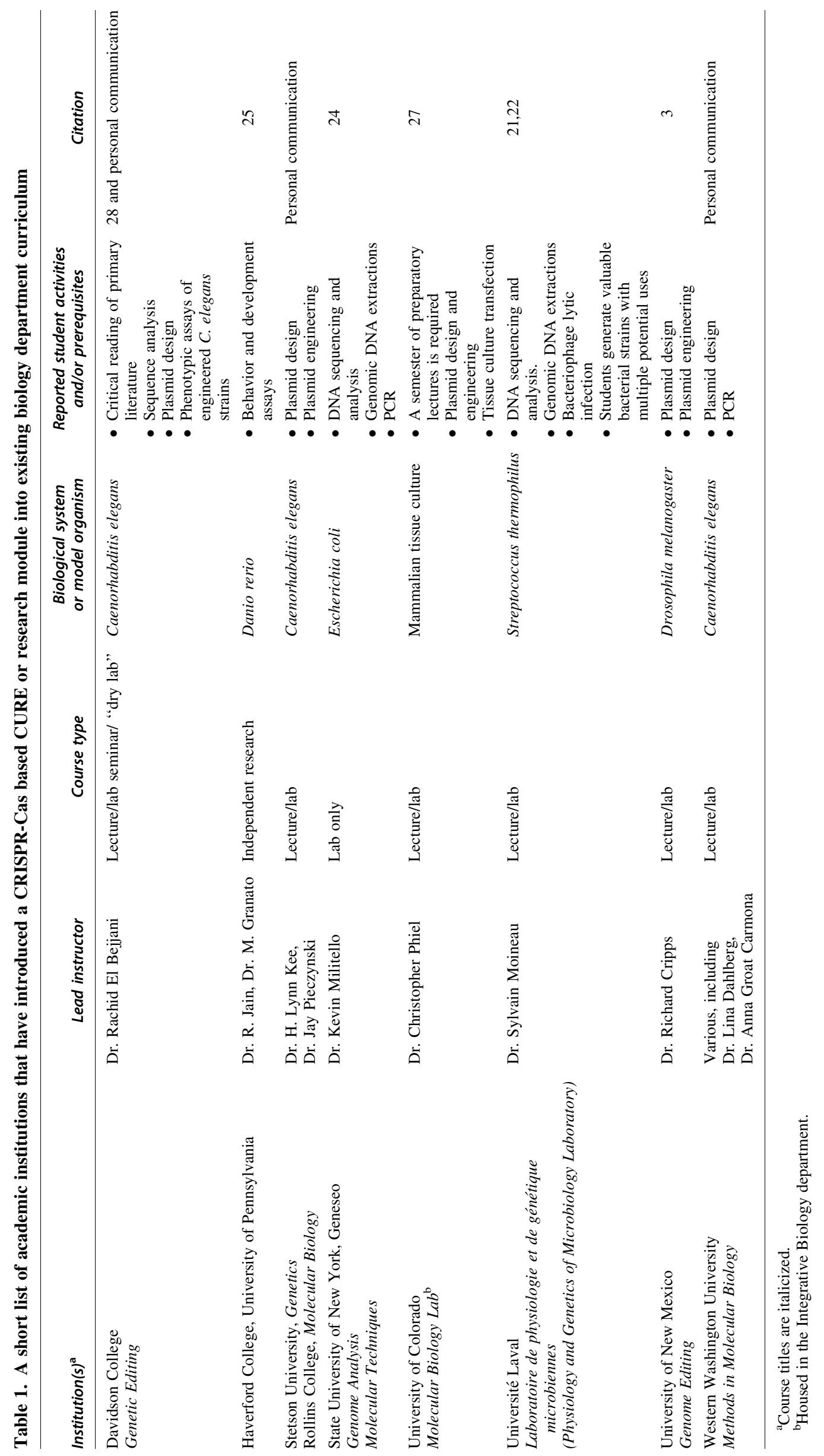


laboratory courses to bolster discussions of the CRISPRCas mechanism and/or the process of science. Davidson College (Davidson, NC) recently introduced a course that explores the technical literature on genome editing and its current uses. There are two variations of the course, one in which primary literature instruction accompanies a series of experiments that allow students to engineer plasmids for genome editing in C. elegans using CRISPR-Cas technology; ${ }^{27}$ the other focuses on sequence analysis, experimental design, and plasmid design in silico. The plasmids and experiments that result from these courses have been used to engineer transgenic worms for research purposes in Dr. Rachid El Bejjani's laboratory (Davidson College, Davidson, NC). The University of Colorado, Denver offers a similar course model. After taking a semester of preparatory lectures, students can participate in a laboratory-based course to introduce CRISPR-Cas into mammalian tissue culture cells as part of Dr. Christopher Phiel's research into the roles of glycogen synthase kinase 3 in mammalian stem cells and epigenetics. ${ }^{28}$ At the University of New Mexico, Albuquerque, students design the CRISPR RNA guides that will eventually be used to knock out an assigned gene of interest in Drosophila. Importantly, although Dr. Richard Cripps only just introduced this course in 2015, he has since published his laboratorybased course model, including the data generated by his students during the course. ${ }^{24}$

Some CUREs allow faculty researchers to generate valuable tools and/or reagents that can be used in independent research projects for students within the faculty member's laboratory. For instance, Dr. Kevin Militello at the State University of New York, Geneseo recently published a paper illustrating the power of his laboratorybased course model wherein students examined the CRISPR loci of uncharacterized E. coli strains. Students were asked to isolate genomic DNA from various $E$. coli strains, amplify the CRISPR locus, and then run DNA sequence analyses in order to identify previously uncharacterized CRISPR loci that can be studied in greater detail later in the future. ${ }^{25}$ The Université Laval (Quebec City, Canada) has also used CRISPR-Cas-based CUREs to further examine the complexities of the CRISPR-Cas system. Dr. Sylvain Moineau's CRISPR-Cas-based CURE investigates natural CRISPR-Cas immunization in Streptococcus thermophilus and introduces students to how bacteria can expand their CRISPR array in response to challenge with virulent bacteriophage. Students can utilize lytic phage infection models and screen surviving $S$. thermophilus cultures for changes in their CRISPR locus using PCR and DNA sequencing. ${ }^{22}$ The benefit of this multifaceted CURE is that it offers many variations with many possible avenues for future exploration since students are generating valuable bacterial strains with multiple potential uses, and indeed this sort of discovery by research laboratories has been particularly important in for the dairy industry. ${ }^{22,23,29}$ A variety of student products from CUREs can therefore contribute to ongoing faculty research programs.

Qualitative and quantitative assessments show that undergraduate students leave CUREs that focus on CRISPR with a better understanding of the principles, research concepts, and applications of CRISPR-Cas technology. ${ }^{22-24,28,30,31}$ Because CUREs that utilize CRISPR-Cas technology are relatively new, there is limited information about how these academic gains translate into student career choices or persistence in scientific (and particularly those involving genetic engineering) fields. However, as the availability of CRISPR-Cas-based CUREs increases, more information regarding the benefits to students will likely become available. Beyond undergraduate engagement, Simon Levien recently published an article with the New Jersey Science Teachers Association that explored some of the benefits of exposing high school students to CRISPR-Cas systems using CUREs, even suggesting low-budget means of introducing the subject matter in advanced placement courses. ${ }^{32}$ Mr. Levien's post regarding the impact that CRISPR-based CUREs have on high school students reflects some of the preliminary data regarding student outcomes resulting from implementing CRISPR-Cas-based CUREs. ${ }^{32}$ In light of the prevalence of CRISPR-Cas technology in the scientific community, offering high school students and undergraduates an opportunity to take part in CRISPR-Casbased CUREs can also have a lasting benefit once students graduate from college and enter the workforce.

\section{Course-Based Research and Institutional Collaborations}

Research opportunities, including CUREs, require intensive planning and can be difficult to implement or change at large research institutions, or at institutions with short instruction periods (i.e., academic quarters). ${ }^{4,13,33}$ However, peripheral interactions with research (in the form of collaborations or contributions) can still provide undergraduate students with a meaningful and flexible way to work as researchers without requiring the planning and implementation of an entire CURE. Scientific collaborations and undergraduate participation in science communication projects can provide another mechanism for students to contribute to both the scientific and lay communities.

A collaboration between researchers at the University of British Columbia (UBC; Vancouver) and at Western Washington University (WWU; Bellingham, WA) provides an example of how collaboration-based research 
A

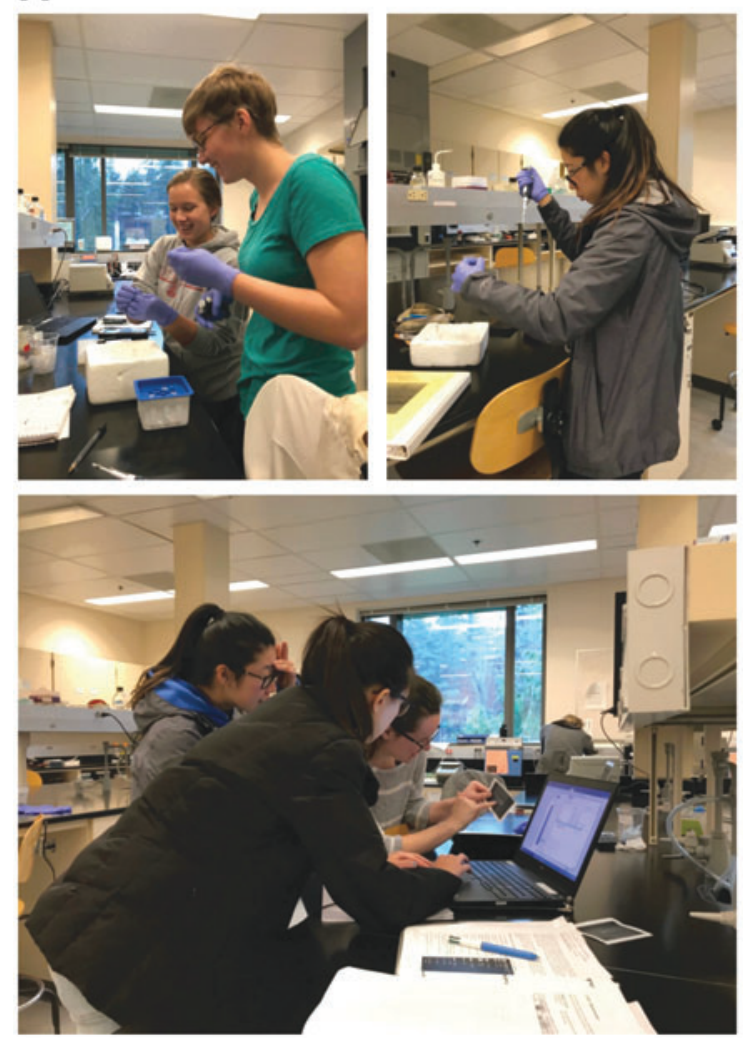

B

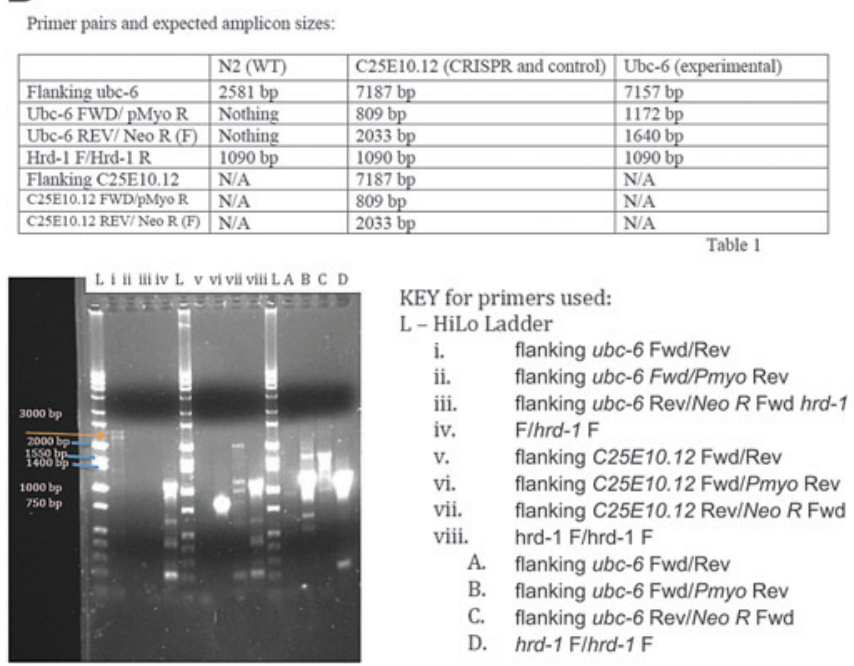

Conclusion(s):

The gel electrophoresis presented the expected results for the correct insertion of the plasmid that can be referenced above in table 1.

The worms did glow green which confirms that the insert was incorporated into the organism's DNA for expression of GFP. With the combination of the PCR results of the band sizes for ubc-6 1 A-D confirms that ubc- 6 - 1 was properly cut by CRISPR-Cas9 and that the inserts were added in the correct orientation (based on primers used in lanes B and C) through homologous recombination.

Lanes $\mathrm{V}$ and $\mathrm{A}$ did not show any bands. This is because the elongation cycle was run for only 2 minutes and 30 seconds, which is not long enough for the expected $7187 \mathrm{bp}$ length. The longest that would show on this particular gel would be approximately 2500 base pairs long.

FIG. 1. Undergraduate students at Western Washington University collaborate with researchers at the University of British Columbia to genotype Caenorhabditis elegans as part of a large-scale CRISPR screen. (A) (Top) Students prepare samples for PCR amplification as part of the quality control PCR protocol. (Bottom) Students analyze their results by comparing DNA fragments on a gel with their predicted sizes. (B) Portions of a student-generated report that details the results of their genotyping experiment. The entire report for each laboratory group is sent to University of British Columbia for their records.

projects can introduce students to CRISPR-Cas technology without requiring a new or fully redesigned course model (Fig. 1A). Students in WWU's molecular biology laboratory course use a variety of molecular techniques in an 11-week introduction to plasmid design and genetic engineering. In addition to being introduced to concepts relating to genome editing, students in this course become accustomed to isolating genomic DNA from various samples (both plants and bacteria) in order to genotype genetically modified organisms using PCR. This course was easily adapted so students use PCR to genotype $C$. elegans strains that are generated as part of a large-scale CRISPR-Cas initiative undertaken at UBC. ${ }^{34}$ While the WWU students do not design the plasmids, or inject the animals, they design and run genotyping PCRs to determine whether the CRISPRCas mediated gene disruption conducted at UBC was successful. This collaborative project gives the students an opportunity to learn about the components that are re- quired for CRISPR-Cas mediated genome editing as well as providing an avenue to ongoing research. As a final project, the students return their annotated genotyping data to the UBC laboratory, which serves as a quality control measure for the $C$. elegans research community at UBC (Fig. 1B). Thus, research opportunities involving CRISPR-Cas technology can be successfully implemented in preexisting laboratory courses, and these efforts can be used to foster collaborations between institutions.

\section{Measuring Success}

Genetic engineering is not trivial, and the molecular techniques required to engineer a transgenic organism depend on knowledge of complex biological systems along with practice to ensure reproducible success. Students engaged in CRISPR-Cas-based CUREs are able to engage in small research projects (Table 1); however, these projects may be left unfinished at the completion of the 

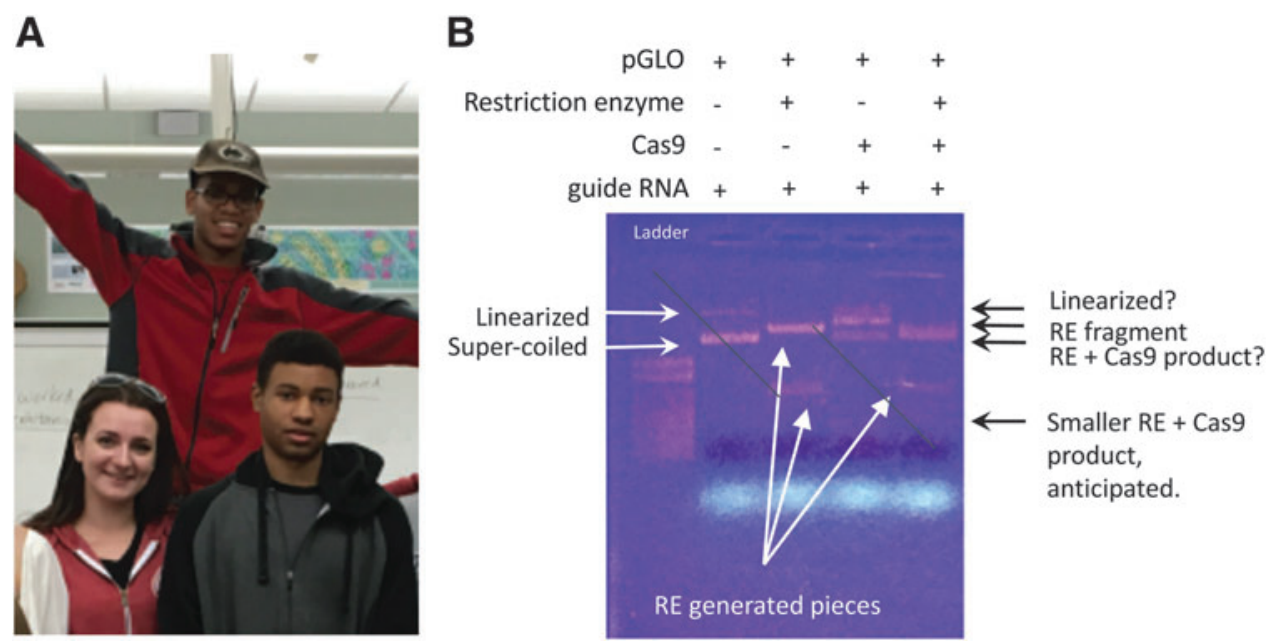

FIG. 2. High school students at Friends' Central High School planned and executed CRISPR-Cas experiments as part of their Biology II course. (A) Students celebrate their time in the laboratory. (B) Annotated results showing that the green fluorescent protein-containing plasmid pGLO (Bio-Rad) was successfully cleaved in the presence of commercial Cas9 and student-made guide RNA. Notably, a "kitchen counter" CRISPR kit was not successful for Friends' Central students. Additionally, the high school class schedule did not permit rerunning or extensive trouble-shooting for either experiment.

course. While incomplete projects may not provide the closure that traditional laboratory courses might, they give realistic insight into the scientific experience, which can prompt students to seek additional research opportunities outside of the classroom. Although data collection on the outcomes of CRISPR-Cas-based CUREs is ongoing, instructors report increased student learning and engagement after implementing CRISPR-Cas-based CUREs using various metrics. ${ }^{21-26}$ Academic institutions have only recently started using CRISPR-Cas-based CUREs in their coursework; with increased interest in CRISPR-Cas-based CUREs, more rigorous studies on student achievement will undoubtedly help inform future activities at more institutions.

\section{Additional Mechanisms for Student Engagement in CRISPR-Cas Technology}

Scientific and other publications are also an accessible entry point for student participation in CRISPR-Cas technology without requiring a redesigned course or ongoing faculty research. We highlight three different examples to illustrate potential avenues (blogs, websites, and peerreviewed publications) for student publication and research dissemination. Haverford College (Philadelphia) students who engaged in summer independent research (Table 1) had the opportunity to write about their experiences conducting independent research via the university's "Speaking of Science" blog. ${ }^{26}$ Similarly, students from Tufts University (Medford, MA) created and published a publicly accessible website on the mechanisms of CRISPR-Cas modification and DNA repair. ${ }^{35}$ While this website is not currently maintained, it is a clear example of students synthesizing their knowledge into a readerfriendly, factually accurate publication. One feature of this website is the comments section, which serves to provide accolades as well as critical feedback to the authors. Finally, many institutions have student-managed newspapers or other campus publications that can be access by potential matriculating students. Utilizing a model similar to those used at Haverford College and Tufts University, students engaged in scientific inquiry could have the opportunity to report their findings or experiences in undergraduate journalism projects to help promote student engagement and course enrollment and provide perspective to the challenges of engaging in student research.

Students can also publish their data from CRISPR-Cas projects in peer-reviewed journals that are geared toward emerging scientists. For example, the Journal of Young Investigators* and Frontiers for Young Minds** publish perspective pieces as well as student research projects. These venues cater to undergraduate (and younger) writers while introducing them to the collaborative and rigorous nature of the peer-review process.

\footnotetext{
*www.jyi.org
}

**https://kids.frontiersin.org 
Student interaction with CRISPR-Cas technology before entering college is also possible, and we offer two examples of inquiry- rather than research-based activities for high school students. In one example, students used their high-school biology course meetings (often only 35 minutes per day, several times a week) to plan in vivo and in vitro approaches to replicating Jennifer Doudna's seminal experiment (highlighted in her iBiology video talk) (Fig. 2A). ${ }^{36}$ Students designed strategies to make guide CRISPR RNAs, transform cells, and in the end, specifically cleave the pGLO plasmid (BioRad) containing the sequence for green fluorescent protein (Fig. 2B). In the second example, students used a commercially available kit (Odin) to induce cleavage of an antibiotic resistance gene. While neither of these examples falls under the category of original research, student responses were overwhelmingly positive. Notably, students reported arriving at college with a firm understanding of the mechanisms behind CRISPR-based technologies and of contextualize the social media-based description of "CRISPR babies" in terms of biological and ethical realities ( $\mathrm{J}$. Punt, University of Pennsylvania, Philadelphia, PA, personal communication).

In light of this last comment, it is also worth highlighting the need to address ethical concerns in studentcentered research endeavors at any level. ${ }^{37}$ The ethics of genome editing (including complex ideas such as gene drives and gene therapy) and scientific research (for example, data collection and analysis, collaboration, and dissemination) are most fruitful when students can grasp the complexities, power, and limitations of molecular techniques and scientific practices. By bringing a discussion of ethics into the classroom or laboratory, instructors can help students make connections between their academic studies, scientific progress, and society. ${ }^{38}$ As students mature, they can become "ambassadors" for science, perhaps initially among their friends and family. Their expertise can begin to inform discussions based on reporting in the lay media in their own social spheres, and then outward to impact society more generally. Direct student engagement with scientific research and writing can become a bridge to opening evidencebased, fruitful discussions on the ethics regarding CRISPR-Cas technologies specifically, and in scientific research, generally.

\section{"Kitchen Counter" CRISPR}

The level of interest in the general public regarding the power of CRISPR-Cas technology is reflected in the flood of news reports, podcasts, magazines, and fictional stories that focus on directed gene editing and its ethics. So-called "kitchen counter" kits for CRISPR-Cas edit- ing, which require no expensive laboratory equipment, are advertised as simple, do-it-yourself opportunities for anyone to work with CRISPR-Cas as gene editing tools (for example, The ODIN). However, while these kits are available to the general public, it is important to note that they are not foolproof. Online reviews from products reflect the fact that even a "failsafe" kit can require troubleshooting. Anecdotally, the previously mentioned high school students were able to recreate a previously published experiment with moderate success (Fig. 2B), but the following year, students found the "kitchen counter" activity more challenging, and did not generate the expected, and advertised, results. As more CRISPR-Casbased CUREs are developed at academic institutions, the nuances of using this system should be communicated to the general public.

\section{Conclusions}

Public and scientific interest in CRISPR-Cas technology and CRISPR-based tools make these fertile areas for student exploration and learning. Research experiences that are dedicated to investigating biological problems using CRISPR-based solutions are already being introduced to undergraduate students through a wide variety of venues. Even more peripheral opportunities, which introduce students to collaborating and communicating, provide valuable information to students and the wider scientific community without requiring entirely new laboratory courses or intensive redesign of existing course. Userfriendly explorations of CRISPR-Cas technology through media and kits also suggest that students can begin to engage in meaningful ways with CRISPR-Cas technologies even before they begin their postsecondary careers. Scientific literacy is one of the most important skills undergraduate students gain as they earn their degrees. By working to provide them with research skills that foster conceptual understanding of cutting-edge research techniques, such as CRISPR-Cas, we will encourage undergraduate students to bring critical reasoning to the public discourse of complex scientific and ethical topics.

\section{Acknowledgments}

We thank B. Wiggins, D. Moerman, R. Fairman, and K. Heston for their helpful discussions and insights, and the instructors of the CUREs that we profiled for providing course materials, descriptions, and clarifications during the preparation of this manuscript. We especially thank J. Punt for her tireless efforts contacting students, M.L. Dahlberg for critical reading of the manuscript, and G.Q. Pennabble for inspiring collaboration. 


\section{Author Disclosure Statement}

No competing financial interests exist.

\section{References}

1. Freeman S, Eddy SL, McDonough M, et al. Active learning increases student performance in science, engineering, and mathematics. Proc Nat Acad Sci U S A. 2014;111:8410-8415. DOI: 10.1073/pnas.1319030111.

2. Bangera G,Brownell SE. Course-based undergraduate research experiences can make scientific research more inclusive. CBE Life Sci Educ. 2014;13:602-606. DOI: 10.1187/cbe.14-06-0099.

3. National Academies of Sciences, Engineering, and Medicine. Undergraduate research experiences for STEM students: successes, challenges, and opportunities. Washington, DC: The National Academies Press, 2017.

4. Auchincloss LC, Laursen SL, Branchaw JL, et al. Assessment of coursebased undergraduate research experiences: a meeting report. CBE Life Sci Educ. 2014;13:29-40. DOI: 10.1187/cbe.14-01-0004.

5. Harrison M, Dunbar D, Ratmansky L, Boyd K, Lopatto D. Classroom-based science research at the introductory level: changes in career choices and attitude. CBE Life Sci Educ. 2011;10:279-286. DOI: 10.1187/cbe.14-01-0004.

6. Hunter A-B, Laursen SL, Seymour E. Becoming a scientist: the role of undergraduate research in students' cognitive, personal, and professional development. Sci Educ. 2007;91:36-74. DOI: 10.1002/sce.20173.

7. Russell SH, Hancock MP, McCullough J. Benefits of undergraduate research experiences. Science 2007;316:548-549. DOI: 10.1126/ science. 1140384.

8. Gregerman SR, Lerner JS, Hippel W von, Jonides J, Nagda BA. Undergraduate student-faculty research partnerships affect student retention. Rev High Educ. 1998;22:55-72. DOI: 10.1353/rhe.1998.0016.

9. iGEM Foundation. International Genetically Engineered Machine Com petition. http://igem.org/Main_Page (last accessed January 16, 2018).

10. Innovative Genomics Institute. Intensive Undergraduate Summer CRISPR Workshop. 2017. https://innovativegenomics.org/events/undergradworkshop-2017/ (last accessed April 10, 2018).

11. The Jackson Laboratory. Summer Student Program. www.jax.org/ education-and-learning/high-school-students-and-undergraduates/ learn-earn-and-explore (last accessed January 16, 2018).

12. Brownell SE, Kloser MJ, Fukami T, Shavelson R. Undergraduate biology lab courses: comparing the impact of traditionally based 'cookbook' and authentic research-based courses on student lab experiences. J Coll Sci Teach. 2012;41:36-45.

13. Howard DR, Miskowski JA. Using a module-based laboratory to incorporate inquiry into a large cell biology course. Cell Biol Educ. 2005;4:249260. DOI: 10.1187/cbe.04-09-0052.

14. Shortlidge EE, Bangera G, Brownell SE. Each to their own CURE: faculty who teach course-based undergraduate research experiences report why you too should teach a CURE. J Microbiol Biol Educ. 2017;18,. pii: 18.2.29. DOI: $10.1128 / \mathrm{jmbe} . v 18 \mathrm{i} 2.1260$.

15. Bradforth SE, Miller ER, Dichtel WR, et al. University learning: improve undergraduate science education. Nature 2015;523:282-284. DOI: 10.1038/523282a.

16. Smith MK, Vinson EL, Smith JA, LewinJD, Stetzer MR. A campus-wide study of STEM courses: new perspectives on teaching practices and perceptions. CBE Life Sci Educ. 2014;13:624-635. DOI: 10.1187/cbe.1406-0108.

17. Cooper KM, Soneral PAG, Brownell SE. Define your goals before you design a CURE: a call to use backward design in planning course-based undergraduate research experiences. J Microbiol Biol Educ. 2017 May 26;18. pii: 18.2.30. DOI: 10.1128/jmbe.v18i2.1287.

18. Rowland S, Pedwell R, Lawrie G, Lovie-Toon J, Hung Y. Do we need to design course-based undergraduate research experiences for authenticity? CBE Life Sci Educ. 2016;15:ar79. DOI: 10.1187/cbe.16-02-0102.

19. Shaffer $C D$, Alvarez $C$, Bailey $C$, et al. The genomics education partnership: successful integration of research into laboratory classes at a diverse group of undergraduate institutions. CBE-Life Sci Educ. 2010;9:55-69. DOI: $10.1187 / 09-11-0087$.
20. Brame CJ, Pruitt WM, Robinson LC. A molecular genetics laboratory course applying bioinformatics and cell biology in the context of original research. CBE Life Sci Educ. 2008;7:410-421. DOI: 10.1187/ cbe.08-07-0036.

21. Jordan TC, Burnett SH, Carson S, et al. A broadly implementable research course in phage discovery and genomics for first-year undergraduate students. MBio 2014;5, e01051-01013. DOI: 10.1128/ mBio.01051-13.

22. Hynes $A P$, Lemay $M L$, Trudel $L$, et al. Detecting natural adaptation of the Streptococcus thermophilus CRISPR-Cas systems in research and classroom settings. Nat Protoc. 2017;12:547-565. DOI: 10.1038/ nprot.2016.186.

23. Trudel L, Frenette M, Moineau S. CRISPR-Cas in the laboratory classroom. Nat Microbiol. 2017;2:17018. DOI: 10.1038/nmicrobiol.2017.18.

24. Adame V Chapapas $\mathrm{H}$, Cisneros $\mathrm{M}$, et al. An undergraduate laboratory class using CRISPR/Cas9 technology to mutate drosophila genes. Biochem Mol Biol Educ 2016;44:263-275. DOI: 10.1002/bmb.20950.

25. Militello KT, Lazatin JC. Discovery of Escherichia coli CRISPR sequences in an undergraduate laboratory. Biochem Mol Biol Educ Biol. 2017;45:262269. DOI: $10.1002 / \mathrm{bmb} .21025$.

26. Zamora, A. Conquering conclusions through zebrafish genetic research Speaking of Science (Blog), August 22, 2016. https://blogs.haverford. edu/speakingofscience/2016/08/22/conquering-conclusions (last accessed April 10, 2018).

27. Dickinson DJ, Pani AM, Heppert JK, Higgins CD, Goldstein B. Streamlined genome engineering with a self-excising drug selection cassette. Genetics 2015;200:1035-1049. DOI: 10.1534/genetics.115.178335.

28. Hildner, V. CRISPR comes to undergraduate molecular biology lab. CU Denver Today, April 4, 2016. www.cudenvertoday.org/crispr-comes-toundergraduate-molecular-biology-lab (last accessed April 10, 2018).

29. Barrangou R, Horvath P. CRISPR: new horizons in phage resistance and strain identification. Annu Rev Food Sci Technol. 2012;3:143-162. DOI: 10.1146/annurev-food-022811-101134.

30. Davidson College. Designer babies and education: The age of CRISPR. Davidson College News, March 18, 2016. www.davidson.edu/news/ news-stories/160318-designer-babies-and-education (last accessed January 16, 2018).

31. Carr S. UNM undergrads among first to train using new genome editing technology. UNM Newsroom, March 31, 2016. https://news.unm.edu/ news/unm-undergrads-among-first-to-train-using-new-genomeediting-technology (last accessed January 16, 2018).

32. Levien S. CRISPR in the classroom by Simon Levien. New Jersey Science Teachers Association, News, July 29, 2017. www.njsta.org/2/post/2017/ $07 /$ crispr-in-the-classroom-by-simon-levien.html (last accessed January 16, 2018).

33. Lopatto D, Hauser C, Jones CJ, et al. A central support system can facilitate implementation and sustainability of a Classroom-based Undergraduate Research Experience (CURE) in genomics. CBE Life Sci Educ. 2014;13:711-723. DOI: 10.1187/cbe.13-10-0200.

34. Moerman C. elegans Gene Knockout Lab, University of British Columbia. www.zoology.ubc.ca/ dgmweb (last accessed January 17, 2018).

35. Cavanagh P, Garrity A. CRISPR/Cas9: Clustered regularly interspaced short palindromic repeats / CRISPR associated protein 9. Tufts Wordpress Blogs and Websites. http://sites.tufts.edu/crispr (last accessed: 16th January 2018).

36. iBiology. Genome engineering with CRISPR-Cas9: birth of a breakthrough technology. www.ibiology.org/genetics-and-gene-regulation/crisprcas9 (last accessed January 16, 2018).

37. Olimpo, J. T., Diaz-Martinez, L. A., Bhatt, J. M. \& D'Arcy, C. E. Integration of RCR and ethics education into course-based undergraduate research experiences in the biological sciences: a needed discussion. $J$ Microbiol Biol Educ. 2017;18. pii: 18.2.45. DOI: 10.1128/ jmbe.v18i2.1344.

38. American Association for the Advancement of Science. Vision and Change in Undergraduate Biology Education: A Call to Action. Final Report, 2011. Available at http://visionandchange.org/finalreport (last accessed April 10, 2018). 